\title{
Study and Development of a Complete System for Recovery, Recycle, and Disposal of Refrigerant Gas from Existent Plants
}

\author{
Corrado Genta, ${ }^{1}$ Carmine Marotta, ${ }^{2}$ and Fortunato Migliardini ${ }^{3}$ \\ ${ }^{1}$ Gas-Tec. S.r.l, V. Vigne Sant'Antonio 51/b, Pompei, 80045 Naples, Italy \\ ${ }^{2}$ General Gas S.r.l, Via Argine 125, 80146 Naples, Italy \\ ${ }^{3}$ Istituto Motori, National Research Council of Italy, Via G. Marconi 4, 80125 Naples, Italy \\ Correspondence should be addressed to Fortunato Migliardini; f.migliardini@im.cnr.it
}

Received 10 October 2016; Revised 3 March 2017; Accepted 15 March 2017; Published 28 March 2017

Academic Editor: Luis Carlos Rabelo

Copyright (C) 2017 Corrado Genta et al. This is an open access article distributed under the Creative Commons Attribution License, which permits unrestricted use, distribution, and reproduction in any medium, provided the original work is properly cited.

\begin{abstract}
The increasing attention of international community towards ozone depletion control and global warming issues has encouraged the development of strategies for emission reduction of fluoridate refrigerant gases. In this context innovative industrial plants able to recover, recycle, and dispose the refrigerant gases need to be developed. In this paper the different phases of design, realization, and characterization of a complete plant for used refrigerant gas recovery are described. The analysis of the pollutants present in the refrigerant stream has supported the design and realization of equipment able to control these emissions and to restore the concentration levels compatible with AHRI standards.
\end{abstract}

\section{Introduction}

Refrigerant gases such as chlorofluorocarbons (CFC), hydrochlorofluorocarbons (HCFCs), and hydrofluorocarbons (HFC) that have dominated the refrigeration and air conditioning sectors for many years contribute significantly to ozone depletion and global warming [1-3]. The high environmental impacts due to halogenated refrigerant emissions has stimulated a wide debate aimed at the identification of efficient strategies for the control of these emissions. Starting from the Montreal treaty of 1987, when a protocol for ozone layer preservation was signed, and passing through Kyoto conference of 1997, where it was demonstrated that most of refrigerants also contribute to global warming [4], the developed countries promoted studies and projects to reduce the production, consumption, and leakage of halogenated refrigerants [5]. Recently refrigerant mixtures having lower environmental impacts with higher energy efficiency have been considered to replace the pure fluids in new plants [6], and the design of new plants able to recover, recycle, and/or dispose all halogenated refrigerants was warmly supported.

In this context General Gas S.r.l., which is an Italian Company Leader in the field of refrigerant gas distribution, together with the company Gas Tech S.r.l. and Istituto Motori of National Research Council of Italy, a no-profit public research organization, has developed experimental research activities aimed at the realization of a complete system for recovery, recycle, and disposal of refrigerant gas from existent plants. In particular the main concern of the above issues has been successfully faced by realizing the following items:

(i) Design and realization of prototype equipment/ method for the recovery of refrigerant gases, characterized by low emission levels and high working reliability

(ii) Pollutant analysis methodology optimization

(iii) Design and optimization of a plant for emission treatment and final storage of regenerated mixtures

The R410A was selected as reference blend for this work; the high working pressure necessary to treat this refrigerant mixture implies the possibility of standardizing the overall procedure also for a large number of other refrigerant mixtures.

In the next paragraphs the above individual phases of the project are described in detail. 


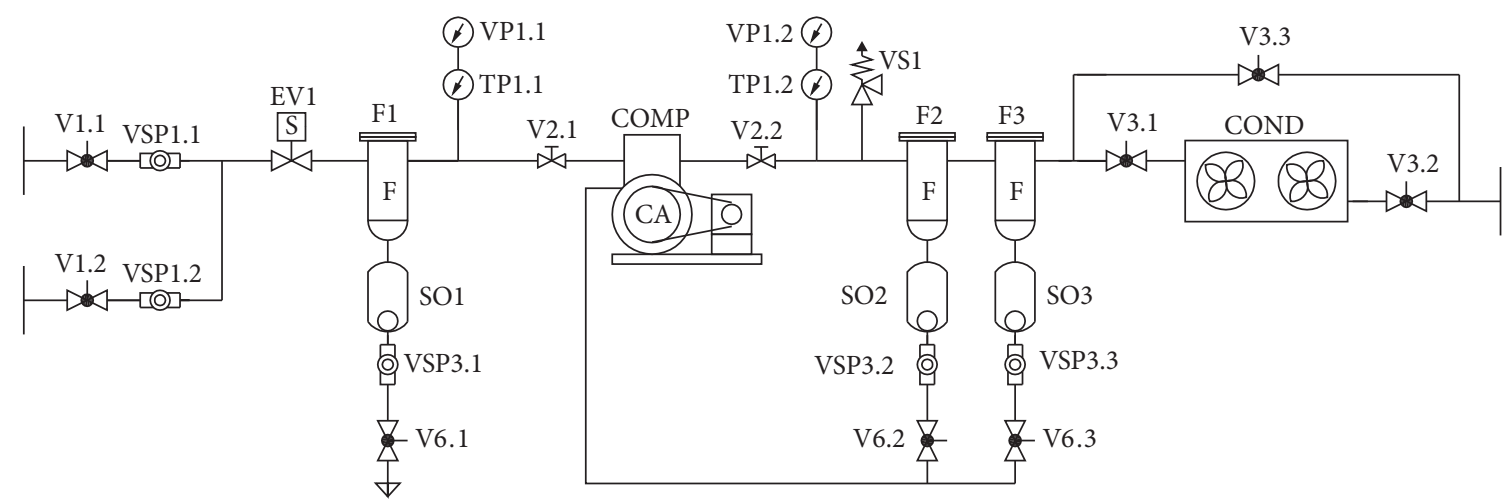

FIGURE 1: Experimental plant for refrigerant gas recovery.

TABLE 1: Specifications for the design of the gas recovery plant.

\begin{tabular}{lc}
\hline Hourly capacity recovery & $120 \mathrm{~kg} / \mathrm{hr}$ \\
Gas pressure & $1-20 \mathrm{bar}$ \\
Particulate matter content & $1 \mathrm{~g} / \mathrm{kg}$ \\
Particulate matter size & $100 \mathrm{micron}$ \\
Humidity maximum content & $1000 \mathrm{ppm}$ \\
Acidity maximum content & $50 \mathrm{ppm}$ \\
Maximum oil content & $3 \%$ \\
\hline
\end{tabular}

\section{Refrigerant Gas Recovery Plant}

The refrigerant gas recovery plant was designed according to the specifications reported in Table 1 . All reported values refer to maximum quantities.

The experimental plant was reported in Figure 1. It is mainly constituted by an open type reciprocating compressor, a condenser, and a sequence of filters able to match the specs reported in Table 1 . The compressor ensures a maximum mass flow rate of about $240 \mathrm{~kg} / \mathrm{h}$ and was inserted between two high efficiency oil separators.

The gas mixture enters into a large section chamber with a fast velocity variation and permits a first separation. Then a double section comprising a grid and a large volume demister, both in stainless steel, permits obtaining very high separation efficiency thanks to velocity and route variations.

The oil separators permit realizing efficiency filtration close to $100 \%$; the device inserted before the compressor permits recycling the oil into the compressor carter. These performances were possible thanks to the cartridge geometry and the coalescence phenomenon. Particle size increases and accumulates on the cartridge surface as beads that fall down for gravity and can be recycled to the compressor. Oil settling is facilitated by a diaphragm that protects the accumulation side from possible reabsorption and turbulence phenomena which can occur on the float of the needle valve.

The analysis of contaminants possibly present in the stream (light hydrocarbons) was performed by a Micro Gas Chromatograph equipped with TCD detector, while oxygen and carbon oxides were determined by online analyzers in a laboratory plant of Istituto Motori. The experimental data permitted detecting negligible $\mathrm{C}_{1}-\mathrm{C}_{4}$ hydrocarbon concentration in the stream to be recovered.

2.1. Plant Realization. The prototype was realized on a specific wheel equipped skin and protected by a safety valve at 25 barg and two pressure sensors placed in compressor suction and discharge, with digital gauges related to threshold values for minimum and maximum pressure.

The high pressure threshold related to the discharge was fixed at 24 barg; if the pressure reaches this value the plant stops and can be manually restarted when the pressure drops below 20 barg. The low pressure threshold related to the suction was fixed at $-0.2 \mathrm{barg}$. In this warning condition the plant stops; the restart occurs only when the suction pressure reaches 0 barg.

A switchboard was realized in order to stop and/or restart the plant and to manage all control parameters.

The device can operate in two working modes: PushPull mode, which permits the emptying of liquid phase accumulated in the plant, and the End Emptying mode, able to complete the emptying operations.

The Push-Pull mode permits extracting the liquid phase from the plant to be emptied. Liquid phase of the plant is linked to the kegs to be filled. Through the prototype a pressure difference arises between the gaseous phase of the plant to be emptied and the kegs where the recovered product had to flow into. In these conditions the pressure of the plant to be emptied is higher than that of the kegs, and because both liquid phases are directly linked, the liquid product flows from the plant to the kegs by pressure difference.

In the End Emptying mode the gas phase of the plant is connected on the suction side of the prototype, while the kegs to be filled are linked on the discharge side. The condenser is not removed because the product is at first condensed; then it is inserted in the kegs.

2.2. Experimental Results. The tests were carried out simulating the plant to be empty and using the kegs containing the contaminated gaseous mixtures.

The experimental results confirmed the high performance of the prototype in terms of oil content, humidity, 
TABLE 2: R410A refrigerant gas analysis before and after recovery.

\begin{tabular}{llcc}
\hline & & Oil content, \% & Oil after recovery, \% \\
\hline Test number 1 & R410A & 3.0 & 0.5 \\
Test number 2 & R410A & 3.1 & n.m. \\
Test number 3 & R410A & 2.2 & 0.3 \\
Test number 4 & R410A & 1.7 & n.m. \\
Test number 5 & R410A & 2.5 & n.m. \\
Test number 6 & R410A & 2.7 & n.m. \\
Test number 7 & R410A & 4.1 & 0.9 \\
Test number 8 & R410A & 1.7 & n.m. \\
Test number 9 & R410A & 3.2 & n.m. \\
Test number 10 & R410A & 3.5 & 0.2 \\
Test number 11 & R410A & 2.2 & n.m. \\
\hline
\end{tabular}

and acidity reduction. In particular the analysis of the oil contained in the plant to be empty is reported in Table 2 together with the analyzed values in the recovered gaseous mixture. The data evidence that in all tests the filtration efficiency is very high. The oil concentration is always lower than $0.9 \%$.

\section{Pollutant Analysis Procedure}

A second important step of the project was the definition of the pollutant analysis procedures. The aim was to monitor the pollutant concentration during the different phases of the stream treatment. In particular the chromatographic technique was selected for noncondensable components and title analysis before and after recovery process.

A portable hygrometer was used for humidity measurements while a titration method was selected for acidity calculation.

3.1. Experimental Analysis Techniques. The experimental analysis was aimed at the evaluation of the pollutant concentration levels present in the stream to be treat and at the determination of the treated and recovered mixture composition in order to verify the possibility of reuse.

The mixture composition control and the analysis of possible other substances into the stream were effected by gas chromatography. Other compounds, unrelated to refrigerant mixture composition, could be detected in the recovered mixtures, as well as noncondensable compounds, such as the air. The presence of these pollutants may be the consequence of a possible incorrect maintenance operation during the life cycle of the plant, or the recovery operations and restraint into the high pressure tanks or kegs, and influence the thermodynamic properties of the mixture.

The gas chromatograph used in the experiments was the Agilent Micro GC 3000, equipped with a TCD detector.

Another important pollutant to be considered is the humidity present in a refrigerant gas; in fact it could cause (i) ice formation during gas expansion, during this phase, characterized by fast temperature drop (it can implicate the thermostatic valve arrest and consequent machine blockage) and (ii) the production of undesirable acidic compounds at the temperature values occurring during the end compression phases (higher than $373 \mathrm{~K}$ ).

Thus it is essential to reduce the humidity content at minimum values. A portable hygrometer Sadp mini dell Alpha Moisture is used for humidity measurements, equipped with a steel filter for the separation of possible liquid traces before the instrument sensor.

The acidity of the mixture that could affect the reliability of the refrigerant plants can be generated by high temperature decomposition of refrigerant compounds, in presence of humidity, as well as by thermal degradation of lubricant oils. The acidity can be also due to failures of electric subsystem such as burn or short-circuit. The acidity was detected by using an organic mixture for extraction and a color toning system. The acidity determination was effected by titration with standard solution of $\mathrm{KOH}$ or $\mathrm{NaOH}$ and expressed in HCL ppm.

In the refrigerator circuit, the refrigerant gas could contact and easily uptake the compressor lubricant oil. Thus a recovered refrigerant mixture could store a significant amount of lubricant oil without any dedicated device. Furthermore some particulate matter can be also found together with oil because of possible decomposition processes of lubricant residuals derived by undesired processing particles.

The experimental evaluation of these high boiling compounds is based on the control of the collected material. An expansion process inside a vessel at room pressure of a wellestablished refrigerant amount (at least $100 \mathrm{ml}$ ) is carried out. Weight and volume of the separated residuals can be then measured inside the container.

The presence of oil can be also verified by supplementary quantitative tests. A Goetz bulb and a graduate steel capillary for refrigerant inlet are used in order to permit the evaporation of a defined quantity of the treated stream. Residual oil accumulates progressively on the bulb bottom, and the graduate scale permits its measurement. Furthermore white sheets of paper and glass surface could evidence possible spots or surface clearness variation, respectively.

3.2. Gas Sample Tests. The gas samples described in Section 2 were used for chromatographic analysis with the aim of evaluating the title and noncondensable gas concentration before and after the recovery operation.

The experimental results of the measurements effected on these samples before and after recovery are reported in Tables 3(a) and 3(b), respectively. The oil concentration before and after recovery operation for each test was reported again.

\section{Plant for Recovered Refrigerant Gas Treatment}

This project phase envisaged the design and realization of a prototype for refrigerant gas treatment able to reduce pollutant levels in the stream. Different processes were considered in order to evaluate all individual steps for the separation of selected pollutant compounds. In particular the following approaches specifically were studied and selected: 
TABLE 3: (a) R410 analysis before recovery operation. (b) R410 analysis after recovery operation.

(a)

\begin{tabular}{|c|c|c|c|c|c|c|}
\hline Oil, \% & Humidity, ppm & Acidity, ppm & Title, \% & $\mathrm{R} 32, \%$ & $\mathrm{R} 125, \%$ & Noncond., \% \\
\hline 3 & 157 & n.m. & 99.99 & 48.07 & 51.92 & 0.45 \\
\hline 3.1 & 299 & n.m. & 99.99 & 48.53 & 51.46 & 0.20 \\
\hline 2.2 & 138 & 155 & 99.99 & 49.63 & 50.36 & 0.27 \\
\hline 1.7 & 311 & 66 & 99.99 & 50.25 & 49.74 & 1.14 \\
\hline 2.5 & 115 & n.m. & 99.99 & 49.91 & 50.08 & 0.27 \\
\hline 2.7 & 197 & n.m. & 99.99 & 49.96 & 50.03 & 0.24 \\
\hline 4.1 & 115 & 199 & 99.99 & 50.53 & 49.46 & 0.17 \\
\hline 1.7 & 95 & n.m. & 99.99 & 49.83 & 50.16 & 1.21 \\
\hline 3.2 & 223 & n.m. & 99.99 & 48.23 & 51.76 & 2.03 \\
\hline 3.5 & 167 & 96 & 99.99 & 50.29 & 49.70 & 0.32 \\
\hline 2.2 & 144 & n.m. & 99.99 & 49.07 & 50.92 & 0.55 \\
\hline
\end{tabular}

(b)

\begin{tabular}{|c|c|c|c|c|c|c|}
\hline Oil, \% & Humidity, ppm & Acidity, ppm & Title, \% & $\mathrm{R} 32, \%$ & $\mathrm{R} 125, \%$ & Noncond., \% \\
\hline 0.5 & 155 & n.m. & 99.99 & 49.84 & 50.15 & 0.40 \\
\hline n.m. & 285 & n.m. & 99.99 & 49.34 & 50.65 & 0.21 \\
\hline 0.3 & 130 & 150 & 99.99 & 50.61 & 49.38 & 0.26 \\
\hline n.m. & 301 & 60 & 99.99 & 49.96 & 50.03 & 0.43 \\
\hline n.m. & 101 & n.m. & 99.99 & 50.19 & 49.80 & 0.21 \\
\hline n.m. & 201 & n.m. & 99.99 & 49.87 & 50.12 & n.m. \\
\hline 0.9 & 117 & 191 & 99.99 & 49.93 & 50.06 & 0.19 \\
\hline n.m. & 96 & n.m. & 99.99 & 49.00 & 50.99 & 0.94 \\
\hline n.m. & 202 & n.m. & 99.99 & 48.77 & 51.22 & 0.38 \\
\hline 0.2 & 160 & 82 & 99.99 & 50.49 & 49.50 & 0.23 \\
\hline n.m. & 102 & n.m. & 99.99 & 49.94 & 50.05 & 0.22 \\
\hline
\end{tabular}

(i) Mechanical filtration to eliminate particulate matter

(ii) Acidity abatement

(iii) A preliminary rough oil separation followed by the coalescence ultrafiltration

(iv) Humidity abatement by adsorption on zeolites

(v) Noncondensable gas treatment by gas under cooling process

4.1. Plant Design. The plant design criteria are then based on the above processes and the overall circuit sizing is determined by the expansion, the compressor group, and the vaporization/condensation units. The scheme of the designed plant is reported in Figure 2, while a photographic view of this plant section is shown in Figure 4.

An inlet valve group (V1.1, V1.2, V1.3, and V1.4) is necessary for connecting the kegs containing the gases to be treated. This stream is pulled out as liquid phase. The stream at the entrance of the plant is firstly expanded thanks to an electronically controlled throttling valve. Then the stream is vaporized by means of a plate-fin heat exchanger, and successively it is compressed and condensed thanks to a fans exchanger. The outlet stream is finally put into specific kegs.
During this cycle the gas is treated to separate the pollutant components. The F1 filter (equipped with a metal mesh cartridge for the particulate elimination) is placed at the inlet of the plant and is able to trap carbonaceous particles up to 50 microns. A further filter equipped with an antacid cartridge (F2) follows filter F1 and is used to reduce the acidity content. Successively the gas is separated by the oil up- and downstream of the compressor. After the condensation the stream is treated for humidity reduction by using a dehydration column. Finally the noncondensable components are separated by means of an undercooling process which utilizes an auxiliary refrigerant circuit. The separation occurs because this circuit permits decreasing the vapor pressure of the same gas by lowering the temperature (see photo of Figure 5).

The maximum mass flow rate capacity of the plant is about $600 \mathrm{~kg} / \mathrm{h}$.

The oil treatment process requires the utilization of two filters places upstream the compressor and two filters downstream the compressor (SO1, SO2, FHE1, and FHE2). The treatment at the inlet section is effected in order to separate the oil present in the initial mixture; the upstream filters are able to reduce the oil content of the stream to be treated. The downstream filters have the role of holding the oil particles dragged by the stream through the compressor 


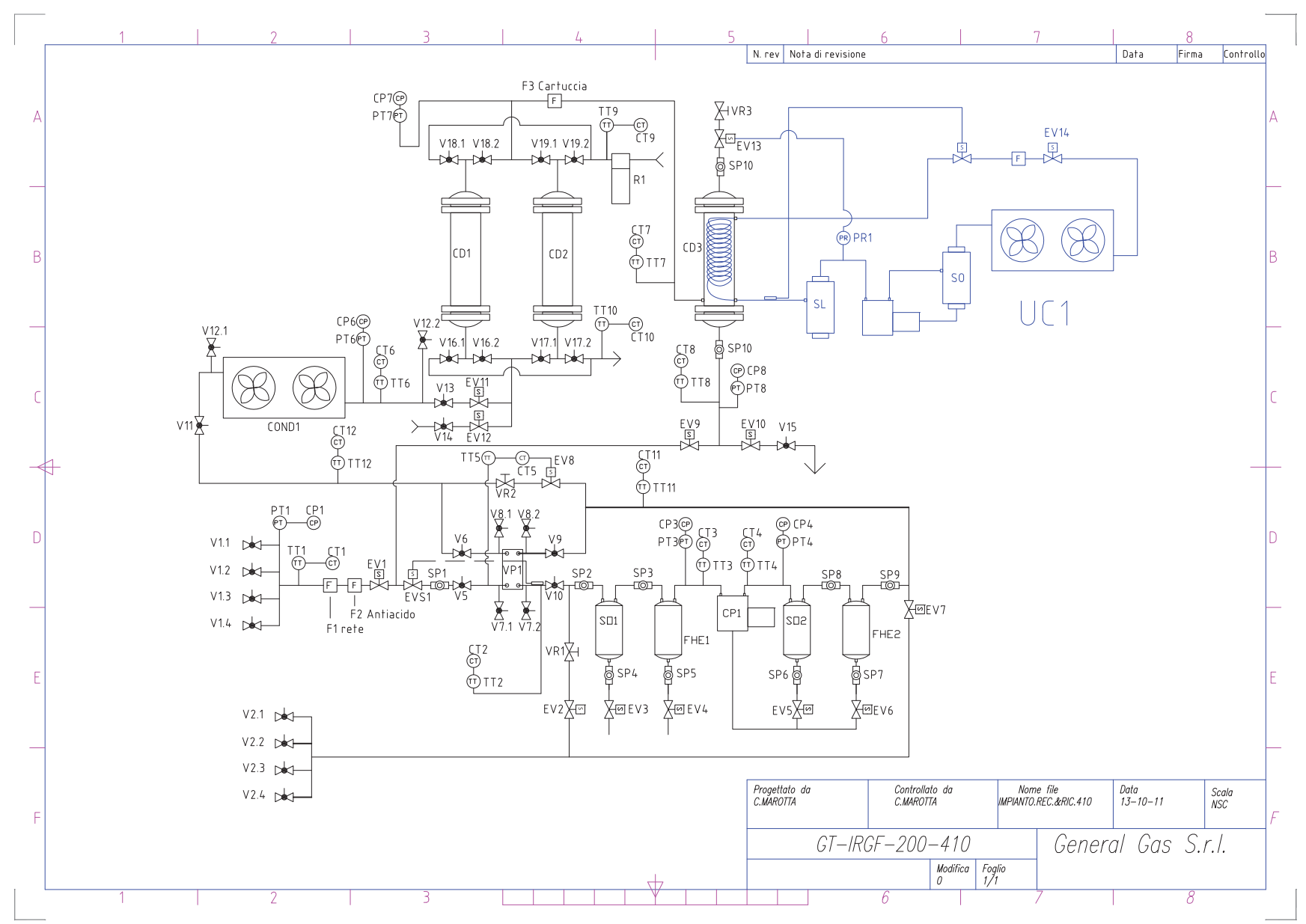

FIGURE 2: Experimental plant for refrigerant gas treatment.

and have to minimize the presence of oil traces. These oil separators permit not only the split by the stream but also the oil recovery with fast integration in the compressor carter.

Different separation techniques were joined in order to obtain the high efficiency of these separators. The first separation phase consists in a rapid expansion of the stream inside a high volume room accompanied by a fast velocity variation. Then a further double section constituted by a grid and a large demister, both in stainless steel, permitted a very high efficiency in oil abatement (up to 95\%) thanks to both velocity and path variations.

The oil settling is accelerated by a diaphragm that protects the underlying accumulation area by potential reabsorption or by turbulence phenomena around the needle valve control float. The separator permits limiting the oil entrainment inside the cleaned stream almost completely (up to 99.9\%), thanks to the cartridge form and the coalescence phenomenon [7].

The separator is also able to clean accidental and carbonaceous particles. The pressure drop minimization can be used as main design criterion for this device, thanks to the high filtration efficiency.

Two columns CD1 and CD2 are designed and assembled in parallel configuration for the aim of regenerating one column while the second goes on regularly. These columns are loaded with zeolites that are molecular sieves particularly active and selective towards water molecules trapping $[8,9]$. The zeolites are crystalline inorganic materials with three dimensionally porous structure and their intracrystalline porosity is characterized by small pore sizes in the range 3-10 A. This characteristic, typical of molecular sieves, permits excluding molecules larger than their diameter. Their adsorption properties are based not only on molecular exclusion based on molecule size, but also on separation based on the selectivity of the surface for polar compounds.

These sieves could be easily regenerated and recycled at the end of the adsorption cycle. In order to obtain a satisfactory regeneration efficiency the temperature of the adsorbent column, during the regeneration phase, could be at about $473 \mathrm{~K}$ for about 4 hours while a stream of $\mathrm{CO} 2$, heated by the R1 resistance (see Figure 2), is pumped inside the emptied column.

In Table 4 the technical data of the two adsorbent columns CD1 and CD2 are reported. The molecular sieves selected as adsorbent materials for refrigeration application are a sodium form of LTA (Linde Type A) zeolites modified by ion exchange with potassium ions (CRYOSIV, Grace Materials Technologies); the sodium form has a pore opening of 

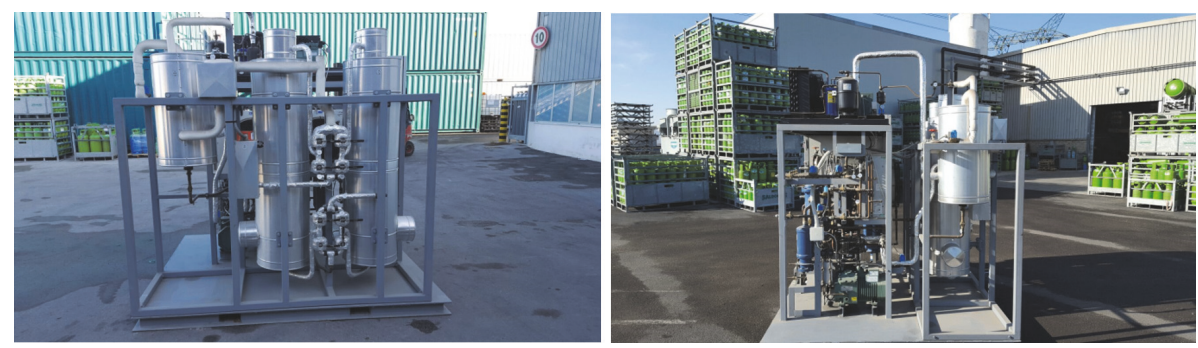

FIGURE 3: Front and lateral view of the integrated plant prototype.

TABLE 4: Technical data of the adsorbent columns CD1 and CD2 of Figure 2.

\begin{tabular}{lc}
\hline Design parameters & \\
\hline Gas velocity & $<0.3 \mathrm{~m} / \mathrm{min}$ \\
Liquid velocity & $0.25 \mathrm{~m} / \mathrm{min}$ \\
Minimum bed length & $1.2 \mathrm{~m} / \mathrm{min}$ \\
Molecular sieve & CRYOSIV, Grace MS594 \\
Sieve capacity & $10 \%$ \\
Sieve density & $790 \mathrm{~kg} / \mathrm{m}^{3}$ \\
\hline Input & \\
\hline Total mass flow rate & $600 \mathrm{~kg} / \mathrm{hr}$ \\
Liquid density at $398 \mathrm{~K}$ & $800 \mathrm{~kg} / \mathrm{m}^{3}$ \\
Max. inlet Humidity & $1000 \mathrm{ppm}$ \\
Max. outlet Humidity & $5 \mathrm{ppm}$ \\
Gas amount for column & $1000 \mathrm{~kg}$ \\
\hline Output & \\
\hline Total volumetric flow rate & $0.375 \mathrm{~m} / \mathrm{hr}$ \\
Water amount to be removed & $0.995 \mathrm{~kg}$ \\
Water flow rate to be removed & $0.299 \mathrm{~kg} / \mathrm{hr}$ \\
Molecular sieve amount & $9.95 \mathrm{~kg}$ \\
Sieve volume & $0.013 \mathrm{~m}$ \\
Calculated column inner diameter & $0.219 \mathrm{~m}$ \\
Commercial column inner diameter & $0.220 \mathrm{~m}$ \\
Bed length & $1.2 \mathrm{~m}$ \\
Column inner volume & $0.046 \mathrm{~m} 3$ \\
Sieve weight & $36.02 \mathrm{~kg}$ \\
\hline
\end{tabular}

approximately 4 Ångstroms while the pore opening of the $\mathrm{K}$ form is reduced to approximately 3 Ångstroms (3 A molecular sieve). These sieves are indicated for drying $\mathrm{Cl}$-free refrigerant streams. This material is highly selective towards water, taking into account the organic compounds present in the refrigerant stream, and has an high drying potential $(<1 \mathrm{ppm})$ in a wide temperature range (up to $373 \mathrm{~K}$ ). Furthermore the spherical particle shape of the product permits realizing a more uniform packed adsorbent bed, reducing the chipping in powders of the particles and minimizing the pressure drop through the bed.

Finally, in order to treat noncondensable gases a copper coil arranged in the column CD3 works as vaporizer of a

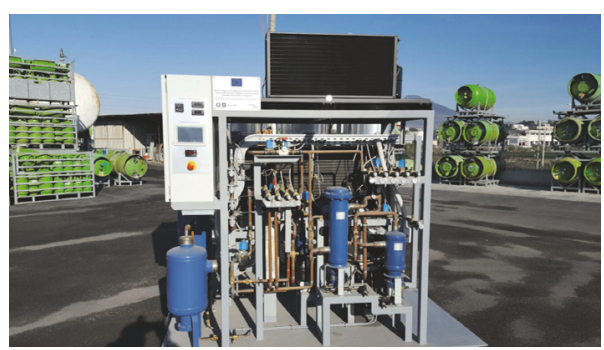

FIGURE 4: View of the plant subsystem for gas treatment.

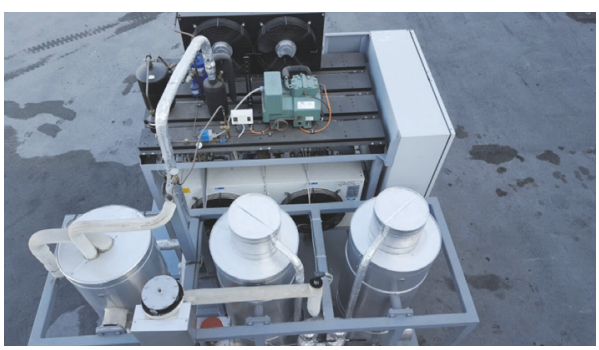

Figure 5: View of the plant subsystem for noncondensable separation.

secondary circuit fed by R507 refrigerant and is used for gas undercooling. This process is optimized by using mineral wool as insulation material. The liquid stream comes in this column and is undercooled by means of the coil, in order to minimize vapor pressure. The noncondensable compounds accumulate in the upper side, reducing the heat exchange between the coil and the stream inside the column. This phenomenon implicates a decrease of the intake pressure of the R507 auxiliary circuit. The accumulated noncondensable gases are finally eliminated by acting a solenoid valve (EV13).

4.2. Prototype Realization and Characterization. The prototype is realized on a trailerable skid. The plant subsystems related to the vaporization, compression, particulate filtration, and oil separation phases are assembled in front of the control panel, while the columns for humidity and noncondensable gas control are placed behind. The secondary refrigerant group is placed on the top of the prototype. Some photos of the plant are shown in Figures 3-5. 
The different components are assembled following the criterion of maintenance and substitution facility, taking into account also the space-saving.

A programmable logic controller (PLC) was used for the integrated system management.

The different working phases of the plant were the following:

(i) Vacuum phase, in order to avoid the air contamination

(ii) Gas treatment phase, according to the technologies described in Section 4.1: at the outlet of the plant a keg accumulated the treated stream, ready for possible analysis

(iii) Recycle phase, useful for recycling the product inside the plant: the keg can be replaced by another one when the maximum weight value of the treated gas keg was reached

The plant is also equipped with a set of alarms that have to intervene during these phases. A manual emergency switch and several alerts to avoid dangerous working conditions of the compressor and of the secondary refrigerant group are mounted for component safety.

An alert at -0.1 bar is installed for the safety of the compressor, at low pressure. The plant restarts automatically when this signal disappeared. Instead, at high pressure the plant must be manually restarted when the emergency has subsided. A further alert with manual restart is mounted for the end compression temperature control.

An operational pressure alert is used for the secondary refrigerant group safety, related to the correct operation of the evaporator inside the column CD3. It is activated when the device does not work because the column is saturated by noncondensable gases. These gases are discharged by opening the EV13 valve and then the alert is turned off.

Some experimental tests are carried out on the realized prototype, in order to verify the expected performance related to the recovered and regenerated stream; the results obtained after regeneration are summarized in Table 5 and can be compared to the results reported in Table 3(b) related to the recovered $\mathrm{R} 410$.

First of all, the data reported in Table 5 suggest that if the plant operates in the right way the final residual oil is practically negligible. The acidity and humidity content result is lower than $5 \mathrm{ppm}$ in regenerated R410, while the mixture title is about $99.99 \%$. Furthermore the noncondensable gas concentration result is lower than $0.03 \%$.

4.3. Experimental Plant for the Final Storage of the Treated Mixtures. The experimental results reported in Tables 3(b) and 5 suggest that the plant for stream regeneration could be easily modified in order to optimize the management strategies for the final storage of the regenerated stream.

The specific design and experimental activities are aimed at producing, for a total mass flow rate up to $600 \mathrm{~kg} / \mathrm{h}$, the following advantages:

(i) Volume reduction during working phases with the possibility of operating on a unique integrated plant
TABLE 5: R410 analysis after regeneration.

\begin{tabular}{lcccccc}
\hline $\begin{array}{l}\text { Oil, } \\
\%\end{array}$ & $\begin{array}{c}\text { Humidity, } \\
\text { ppm }\end{array}$ & $\begin{array}{c}\text { Acidity, } \\
\text { ppm }\end{array}$ & $\begin{array}{c}\text { Title, } \\
\%\end{array}$ & $\begin{array}{c}\text { R32, } \\
\%\end{array}$ & $\begin{array}{c}\text { R125, } \\
\%\end{array}$ & $\begin{array}{c}\text { Noncond., } \\
\%\end{array}$ \\
\hline n.m. & 4 & n.m. & 99.99 & 49.87 & 50.15 & 0.02 \\
n.m. & 3 & n.m. & 99.99 & 49.60 & 50.61 & 0.02 \\
0.02 & 3 & 3 & 99.99 & 50.66 & 49.41 & 0.01 \\
n.m. & 2 & 2 & 99.99 & 50.01 & 50.07 & 0.02 \\
n.m. & 4 & n.m. & 99.99 & 50.10 & 49.83 & 0.01 \\
n.m. & 4 & n.m. & 99.99 & 49.97 & 50.22 & n.m. \\
0.01 & 2 & 3 & 99.99 & 49.96 & 50.01 & 0.01 \\
n.m. & 3 & n.m. & 99.99 & 49.24 & 50.87 & 0.01 \\
n.m. & 3 & n.m. & 99.99 & 48.99 & 51.01 & 0.02 \\
0.01 & 2 & 1 & 99.99 & 50.49 & 49.80 & 0.01 \\
0.02 & 4 & n.m. & 99.99 & 49.94 & 50.10 & 0.01 \\
\hline
\end{tabular}

(ii) Possibility of realizing simultaneously both regeneration and final storage operations

(iii) Easy handling and movements of the kegs and the tanks containing the different streams and components

The plant described in the previous section, used for exhaust refrigerant treatment, has permitted reestablishing its high purity level, useful for a successive reuse in industrial refrigerant group. On the other hand the composition of the recovered mixture needs to become compatible with the standard specifications defined for all refrigerants (AHRI standard $700[10])$.

In this regard a system able to restore the correct composition of the regenerated mixture by addition of calculated quantities of individual components was finally developed.

The design of this equipment (a scheme is shown in Figure 6) has required a volumetric pump to extract the gas from the barrel containing the component and to insert it into the mixture. If necessary the plant permits adding additional components by barrel substitution. The plant can operate with product volumetric flow rate up to $5 \mathrm{~m}^{3} / \mathrm{h}$ and foresees the utilization of internal gear pump, able to operate up to pressures of about 40 bar. A dedicated system for the correct amount processing was developed in order to realize an automatic control of the phases for the final regeneration. In particular a load cell was interfaced with the plant control processor, permitting calibrating the addition of the specific component.

Ultimately the different steps for the final storage can be summarized as follows:

(i) Gas-chromatographic analysis of all pollutants (see Section 3)

(ii) Gas treatment (see Sections 3 and 4.2)

(iii) Gas-chromatographic analysis of the composition of the treated mixture

(iv) Comparison between AHRI tables and treated mixtures, in order to verify the possibility of restoring a refrigerant mixture ready for its reuse 
TABLE 6: Gas analysis before and after regeneration.

\begin{tabular}{lccccc}
\hline \multirow{2}{*}{$\begin{array}{l}\text { Initial mixture weight } \\
\mathrm{kg}\end{array}$} & $\mathrm{R} 32, \%$ & $\mathrm{R} 125, \%$ & $\mathrm{R} 32, \mathrm{~kg}$ & $\mathrm{R} 125, \mathrm{~kg}$ & Basic components to be added for standard specs \\
\hline 602.00 & 60.40 & 39.60 & 363.6 & 238.4 & $\mathrm{R} 125,125.2 \mathrm{~kg}$ \\
513.00 & 36.58 & 63.42 & 187.7 & 325.3 & $\mathrm{R} 32,137.7 \mathrm{~kg}$ \\
588.00 & 53.11 & 46.89 & 312.3 & 275.7 & $\mathrm{R} 125,36.6 \mathrm{~kg}$ \\
441.00 & 46.36 & 53.64 & 204.5 & 236.6 & $\mathrm{R} 32,32.1 \mathrm{~kg}$ \\
\hline Final mixture weight & \multicolumn{5}{c}{ Mixture final composition } \\
\hline 727.2 & 50.20 & 49.80 & 365.1 & 362.2 \\
650.7 & 49.68 & 50.32 & 323.3 & 327.4 & 313.9 \\
624.6 & 49.74 & 50.26 & 310.7 & 235.0 & \\
473.1 & 50.32 & 49.68 & 238.1 &
\end{tabular}

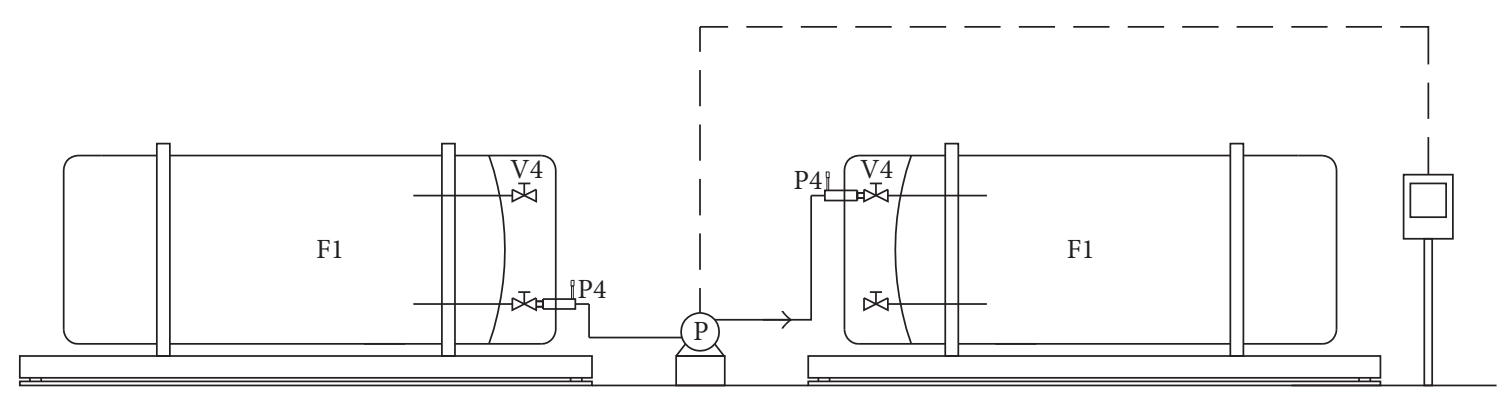

FIGURE 6: Scheme of the equipment to maintain the refrigerant mixture composition.

(v) Addition of individual selected components, thanks to the specific plant of Figure 3

The experimental verification of the plant performance for final storage of regenerated streams was carried out by integration tests of pure components extracted by kegs, in order to restore the type composition of the R410A mixture.

Regarding the R32-R125 mixtures, AHRI standards recommend realizing $\mathrm{R} 32$ concentration values ranging from 48.5 to $50.5 \%$. Then the concentration values of the R125 component range from 49.5 to $51.5 \%$. In Table 6 the experimental data related to the mixture analysis are reported in terms of initial compositions and final compositions after regeneration phases.

\section{Conclusions}

A plant prototype for the recovery of exhaust refrigerant gas mixtures was developed according to the following specs:

(i) Hourly capacity recovery of $120 \mathrm{~kg} / \mathrm{hr}$

(ii) A relative gas pressure of these gases in the range 1-20 bar

(iii) A maximum residual oil content of $3 \%$

(iv) An equipment weight not higher than $400 \mathrm{~kg}$

This equipment was able to reduce almost completely the residual oil content of the recovered refrigerant gas mixture.
The experimental results obtained with $\mathrm{R} 410 \mathrm{~A}$ showed that a residual oil concentration inferior to $1 \%$ could be always reached.

Furthermore a second plant was realized for refrigerant gas treatment and for the final storage of the regenerated mixture. This plant was equipped with several subsystems for

(i) acidity and particulate matter abatement,

(ii) a first rough oil separation and a successive ultrafiltration phase,

(iii) humidity control by adsorption on molecular sieves,

(iv) noncondensable gas elimination by gas supercooling.

The selected methodologies and techniques for pollutant analysis and abatement were successfully used for the design of this equipment.

The tests carried out on the final plant for the storage of regenerated mixtures permitted verifying the practical possibility of restoring highly pure mixtures compatible with the expected tolerance ranges of AHRI standards.

\section{Conflicts of Interest}

The authors declare that they have no conflicts of interest. 


\section{Acknowledgments}

The authors gratefully acknowledge the Campania Region of Italy for financial support (Regional Operative Plan 3.17) and the Eng. Scarano for technical support in adsorbent column design.

\section{References}

[1] M. J. Molina and F. S. Rowland, "Stratospheric sink for chlorofluoromethanes: chlorine atom-catalysed destruction of ozone," Nature, vol. 249, no. 5460, pp. 810-812, 1974.

[2] F. S. Rowland, "Earth's changing atmosphere: chlorofluorocarbons and ozone," Environmental Impact Assessment Review, vol. 10, no. 4, pp. 359-370, 1990.

[3] M. Mohanraj, S. Jayaraj, and C. Muraleedharan, "Environment friendly alternatives to halogenated refrigerants-a review," International Journal of Greenhouse Gas Control, vol. 3, no. 1, pp. 108-119, 2009.

[4] E. Johnson, "Global warming from HFC," Environmental Impact Assessment Review, vol. 18, no. 6, pp. 485-492, 1998.

[5] I. P. Koronaki, D. Cowan, G. Maidment et al., "Refrigerant emissions and leakage prevention across Europe-results from the RealSkillsEurope project," Energy, vol. 45, no. 1, pp. 71-80, 2012.

[6] M. Mohanraj, C. Muraleedharan, and S. Jayaraj, "A review on recent developments in new refrigerant mixtures for vapour compression-based refrigeration, air-conditioning and heat pump units," International Journal of Energy Research, vol. 35, no. 8, pp. 647-669, 2011.

[7] Y. Liao and D. Lucas, "A literature review on mechanisms and models for the coalescence process of fluid particles," Chemical Engineering Science, vol. 65, no. 10, pp. 2851-2864, 2010.

[8] D. W. Breck, Zeolite Molecular Sieves: Structure, Chemistry, and Use, John Wiley \& Sons, New York, NY, USA, 1974.

[9] R. T. Yang, Adsorbents: Fundamentals and Applications, WileyInterscience, 2003.

[10] Standard for Specifications for Refrigerants, 2015, http://www .ahrinet.org/App_Content/ahri/files/standards\%20pdfs/AHRI\% 20pdfs/AHRI\%20standards\%20pdfs/AHRI_Standard_700-2015 .pdf. 


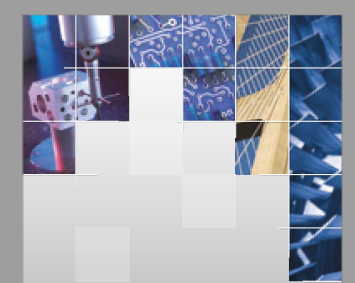

\section{Enfincering}
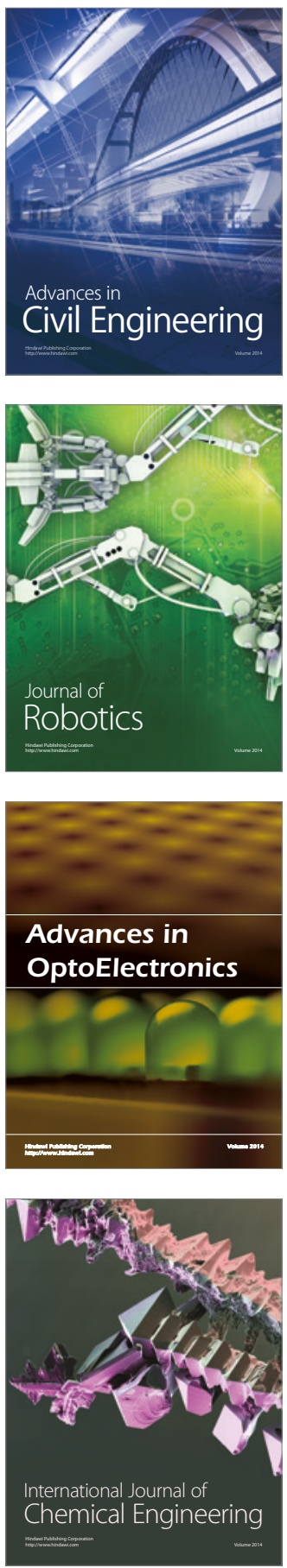

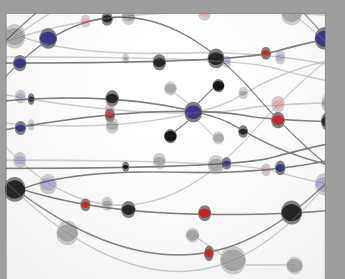

The Scientific World Journal

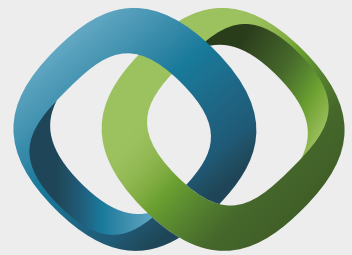

\section{Hindawi}

Submit your manuscripts at

https://www.hindawi.com
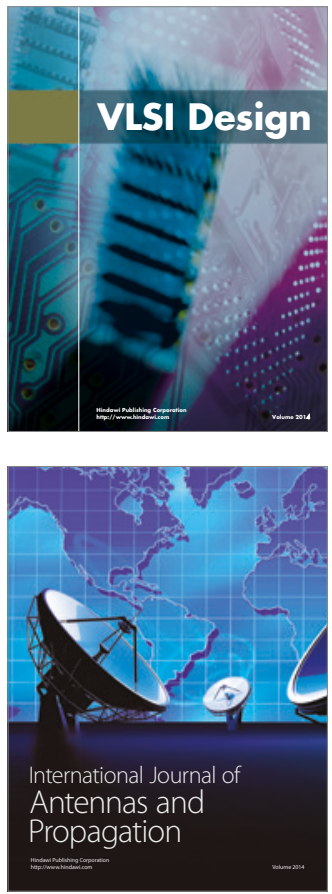

\section{Rotating}

Machinery
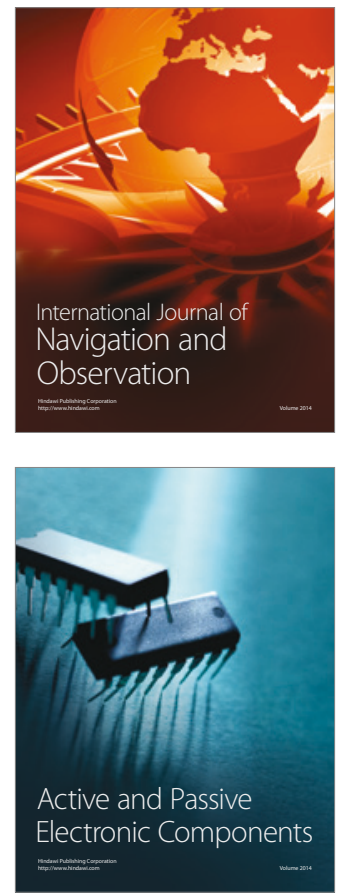
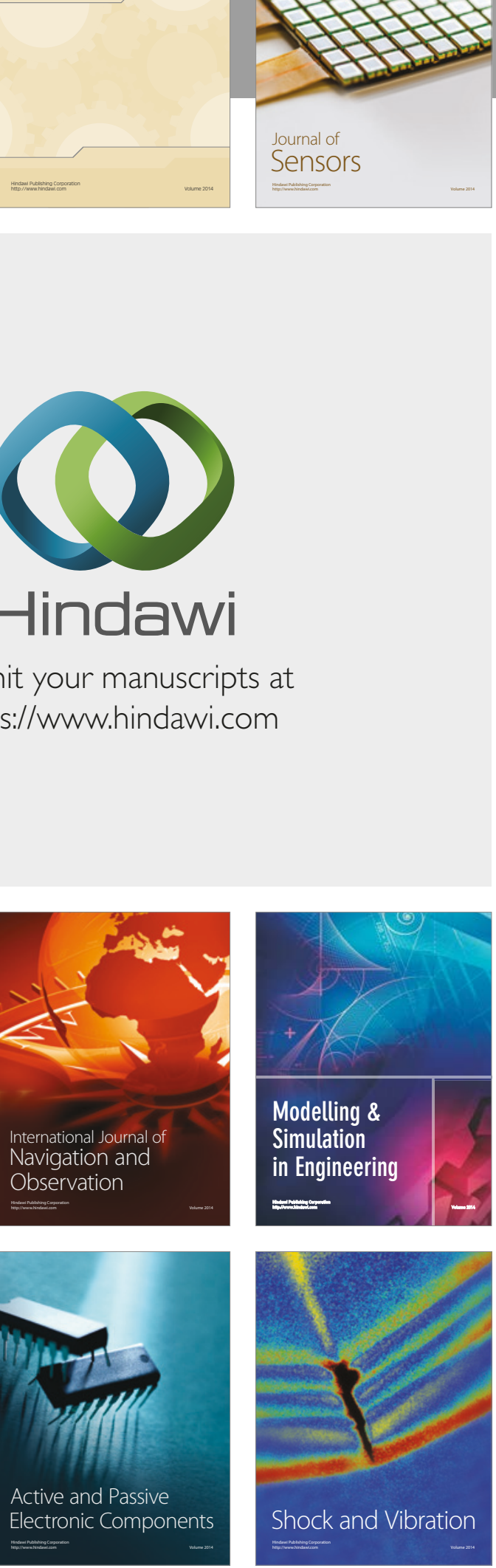
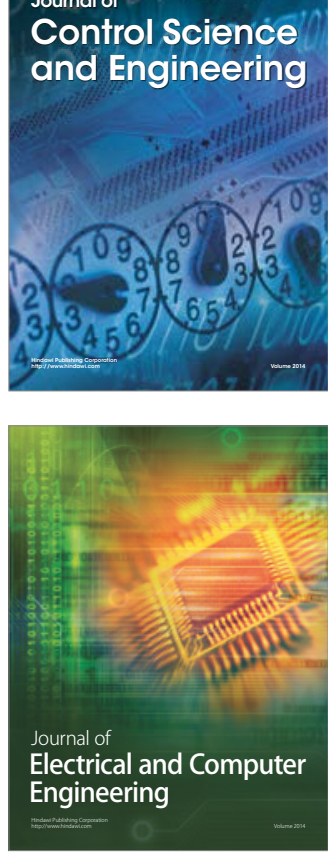

Distributed

Journal of

Control Science

and Engineering
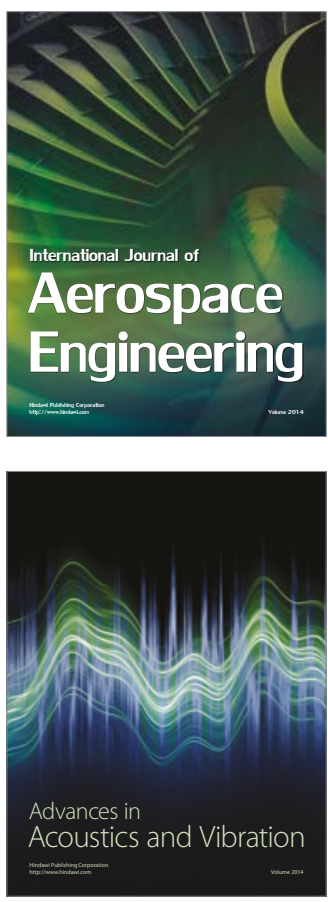

Sensor Networks 